\title{
Specify Other Non-Neoplastic Finding
}

National Cancer Institute

\section{Source}

National Cancer Institute. Specify Other Non-Neoplastic Finding. NCI Thesaurus. Code C159870.

A directive to specify the other non-neoplastic finding. 